\title{
Relationship between Head Nurses Emotional Intelligence and Staff Nurses Job Satisfaction
}

\author{
MAHA M. MOHAMMED, M.Sc. and NEHAD E. FEKRY, D.N.Sc. \\ The Department of Nursing Administration, Faculty of Nursing, Cairo University
}

\begin{abstract}
Background: Emotional intelligence has been used by the administrative authorities in many workplaces to explain issues related to the job satisfaction, performance, absenteeism, organizational commitment and leadership. In the context of the emerging 'affective revolution' in social and organizational psychology, emotional intelligence is proposed as an important predictor of key organizational outcomes including job satisfaction. It is a basic requirement in any profession that is based on human relations especially in nursing. Emotions play an important role in the nursing profession which requires both technical expertise and psychologically oriented care. Aim: the current study assesses the relationship between head nurses emotional intelligence and staff nurses' job satisfaction.
\end{abstract}

Subjects and Methods: A descriptive correlational design was utilized for this study to achieve the stated aim. Setting: The study was conducted at New Kaser El-Aini Teaching Hospital.

Two groups of sample were invited to participate in the questionnaire as follows. First group all head nurses who were working in inpatient department their number was (30). The second group is all staff nurses in the previous departments; their number was (350). Data was collected by using the following two tools: Emotional intelligence questionnaire and job satisfaction questionnaire.

Results: There was a high level of emotional intelligence among head nurses as well as there was a moderate level of job satisfaction.

Conclusion: There was a positive relationship between head nurses emotional intelligence and staff nurses' job satisfaction.

Recommendation: Measure staff nurses job satisfaction in a regular base in order to find out areas of satisfaction to promote and areas of dissatisfaction to solve and improve. Also the study recommended to give opportunities for further research should be made to investigate factors that affect emotional intelligence and job satisfaction.

Key Words: Emotional - Intelligence - Job satisfaction.

Correspondence to: Dr. Maha M. Mohammed, The Department of Nursing Administration, Faculty of Nursing, Cairo University

\section{Introduction}

THE main objective of any profitable organization should be to make a profit. This objective can only be achievied by increasing the employees' performance, which is subsequently related to emotional itelligence (EI) and job satisfaction. The studies on the relationship between EI and job satisfaction are becoming prevalent in the academic literature [1] . Nursing is a health care profession, which is focused on the care of individuals, families and communities; so that they can attain, maintain or recover optimum health. Nurses care for individual of all ages and cultural backgrounds who are healthy and ill in a holistic manner based on the individual's physical, emotional, psychological, intellectual, social and spiritual needs [2].

Emotional intelligence (EI) is the capacity, skill, ability or in the case of the trait emotional intelligence model it is a self-perceived ability which helps in order to control, access and identify the emotions of himself/herself, of others and of different groups [3].

Emotional intelligence is important to consider the effects of managing up, which refers to the good and positive relationship between the employee and his/her supervisor. Previous research found that quality of this relationship could interfere in the results of the subjective rating of job performance evaluation. Emotional intelligent supervisors devote more of their working time on managing their relationship with employee's supervisors [4]

Job satisfaction is determined by a comparison of one's prior expectations about the job and the actual experience of the job. It has been found that job satisfaction relates to beliefs and emotions that individuals have about their work and their job. It has been described as an attitude with an affective 
and cognitive component. When establishing the level of job satisfaction, we should focus on how employees feel about their work and personal relationships in the workplace, and on how leaders influence employees' satisfaction. Without a doubt, satisfied employees are the ultimate goal of every leader. On the other hand, the goal of every employee is to find the kind of work that matches their abilities and interests as closely as possible, enables them success, and provides them with opportunities for promotion. Satisfied employees tend to be more productive and committed to their employers [5].

It is generally considered that employees with higher emotional intelligence will influence job satisfaction. This is because the employees with higher emotional intelligence are able to develop strategies to overcome the possible consequences which may arise out of stress whereas those with less emotional intelligence won't be in a position to overcome the stress situations. In addition, in a group setting employees with higher EI will be able to influence the emotions of others in such a manner that, they will be able to boost their own as well as their coworkers morale.

The relationship between emotional intelligence and job satisfaction has gained the attention of researchers as it is reported that emotional intelligence plays a pivotal role in predicting job satisfaction among employees [6]

\section{Significance of the study:}

Studies concluded that EI has been playing vital role in today's working environment. The philosophy of EI assists in analyzing employee's attitude, styles of management, interpersonal capabilities and job satisfaction. It testifies a significant relevance in head nurses practices like selection and recruitment, planning and profiling [7] The most important advantage of EI is that it helps the employees to comprehend and manage sentiments. It also provides an area to a person to become handy of his own conduct as well as associations with the people around. Psychological research revealed that, comprehending and managing emotions play important and pivotal role in rewarding person's everyday life and work setting [8]

Therefore the present study aiming to assess the level of emotional intelligence of head nurses and its relationship to the level of job satisfaction of staff nurses in order to spot light on areas which could be developed in emotional intelligence of the head nurses to improve the level of job satis- faction of staff nurses, quality of performance and to achieve the hospital goals.

\section{Research questions:}

- What are the levels of emotional intelligence of the head nurses?

- What are the levels of job satisfaction of the staff nurses?

- What is the relationship between head nurses emotional intelligence and staff nurses' job satisfaction?

\section{Subject and Methods}

\section{Research design:}

Descriptive correlational design was utilized to achieve the aim of this study.

\section{Setting:}

The current study was carried out at New ElKasr El-Aini teaching hospital from Jan. 2017 to August 2017.

\section{Subjects:}

Two groups of sample were invited to participate in the questionnaire as follows. First group all head nurses who were working in inpatient department in the mentioned hospital their number was (30). The second group is all staff nurses in the previous departments; their number was (350).

\section{Tools of data collection:}

It is composed of two tools as follows: 1st Tool:

Emotional intelligence questionnaire which composed of two parts.

A- Head nurses personal characteristics data: This included data about participant regarding age, sex, marital status, years of experience in nursing and years of experience as a head nurse.

B- Emotional intelligence questionnaire this was developed by [9]. It was used to collect data about emotional intelligence of head nurses. It was likert scale of 5 points to measure respondents' opinions regarding self awareness (7 items), emotional self regulation (8 items), self motivation (7 items), empathy (11 items), social awareness (11 items). Stress management (28 items) and self esteem: (17 items).

\section{2nd Tool:}

This tool was devolved by [10] and modified by the researcher and was used to collect data about job satisfaction of staff nurses this tool composed of two parts: 
A- Personal characteristics data this included data about participant regarding age, sex, educational level, years of experience in nursing and working department.

B- Nurses' Job Satisfaction questionnaire liker scale of 5 points to measure respondents' opinions regarding supervision (7 Items), nature of the work (4 Items), communication (4 Items), co-worker relationship (4 Items), promotion (6 Items), and work pressure (3 Items).

\section{Methods of data collection:}

- Consent to conduct the study was taking from the vice dean of graduate studies at Faculty of Nursing, Cairo University and Hospital Administrator.

- The tools were reviewed by jury consisted of five professors in nursing administration to be tested for its content validity.

- The investigator contacted to the nurses to explain the purpose and procedure of the study and determine the available time to collect data.

- The questionnaires were distributed to the studied sample during morning, afternoon and night shifts.

- Data collection was completed over a seven months period from Jan. 2017 to August 2017.

\section{Ethical considerations:}

Before commencing the study, ethical approval was granted from the research ethics committee in which the study took place. The researchers ensured that the correct procedures were undertaken concerning informed consent, autonomy, anonymity and the maintenance of confidentiality.

\section{Statistical analysis:}

The collected data will be categorized, scored, tabulated, and analyzed by computer using statistical package for social science (SPSS). Descriptive statistics will be used in the form of frequency distribution and percentages. Appropriate statistical test were applied for data analysis.

\section{Results}

Table (1) show that $(66.6 \%)$ of head nurses were females, while $(43.3 \%)$ of them were in the age group ranged from 30 to less than 40 years old. About $(93.3 \%)$ of the study sample were married. And about $(63.3 \%)$ had years of experience as a staff nurse ranged between 10 to less than 20 years, while $93.3 \%$ of them had years of experience as a head nurse ranged between 1 to less than 10 years.
Table (2) shows that the highest mean percentage for head nurses emotional intelligence was about $(89.42 \%)$ agreed with the presence of self awareness followed by about $(88.48 \%)$ agreed with the presence of empathy and only (73.29\%) agreed with the presence of self-esteem.

Table (3) shows that the majority (93.3\%) of head nurses had high emotional intelligence and only $(6.7 \%)$ had moderate emotional intelligence.

Table (4) show that $(77.4 \%)$ of staff nurses were females, while (33.1\%) of them were in the age group ranged from 20 to 30 years old. About $(56 \%)$ had diploma in nursing and $(31.5 \%)$ of them had years of experience ranged between 1 to less than 10 years.

Table (5) shows that the highest mean percentage for the staff nurses job satisfaction about (70\%) agreed with the presence of work pressure and presence of coworker relationship and only (62. $42 \%$ ) of them agreed with the presence of work promotion.

Table (6) shows that the majority $(80.8 \%)$ of staff nurses have moderate level of job satisfaction while, only (19.2\%) of them have high job satisfaction.

Table (7) shows that there was positive relationship between job satisfaction and emotional intelligence $(r=0.359, p=0.052)$.

Table (1): Distribution of head nurses according to demographic characteristics $(\mathrm{N}=30)$.

\begin{tabular}{|c|c|c|}
\hline Item & No. & $\%$ \\
\hline \multicolumn{3}{|l|}{ Gender: } \\
\hline Male & 10 & 33.3 \\
\hline Female & 20 & 66.7 \\
\hline \multicolumn{3}{|l|}{ Age: } \\
\hline $30<40$ years & 13 & 43.3 \\
\hline $40<50$ years & 12 & 40 \\
\hline 50 -above 50 years & 5 & 16.7 \\
\hline \multicolumn{3}{|l|}{ Marital status: } \\
\hline Married & 28 & 93.3 \\
\hline Single & 2 & 6.7 \\
\hline \multicolumn{3}{|c|}{ Years of experience as a staff nurse: } \\
\hline $1<10$ & 5 & 16.7 \\
\hline $10<20$ & 19 & 63.3 \\
\hline 20 to more than 20 & 6 & 20.0 \\
\hline \multicolumn{3}{|c|}{ Years of experience as a head nurse: } \\
\hline $1<10$ & 28 & 93.3 \\
\hline $10<20$ & 2 & 6.7 \\
\hline 20 to more than 20 & 0 & 0 \\
\hline
\end{tabular}


Table (2): Mean and standard deviation and mean percent of respondent's perception about emotional intelligence dimension $(\mathrm{N}=30)$.

\begin{tabular}{lccccc}
\hline $\begin{array}{l}\text { Emotional } \\
\text { intelligence }\end{array}$ & $\begin{array}{c}\text { Mini- Maxi- } \\
\text { mum mum }\end{array}$ & Mean & SD & $\begin{array}{c}\text { Mean } \\
\%\end{array}$ \\
\hline Self-awareness & 7 & 35 & 31.3000 & 1.76459 & 89.42 \\
$\begin{array}{l}\text { Emotional } \\
\quad \text { self-regulation }\end{array}$ & 8 & 40 & 33.1333 & 3.18112 & 82.83 \\
Self-motivation & 7 & 35 & 30.66 & 2.19307 & 87.62 \\
Empathy & 11 & 55 & 48.6667 & 3.94211 & 88.48 \\
Social awareness & 11 & 55 & 48.0000 & 2.86477 & 87.72 \\
Stress management & 28 & 140 & 122.1000 & 7.97993 & 87.21 \\
Self-esteem & 17 & 85 & 62.3000 & 4.26817 & 73.29 \\
Total emotional & 90 & 450 & 380.2667 & 18.98263 & 84.5 \\
$\quad$ intelligence & & & & & \\
\hline
\end{tabular}

Table (3): Frequency distribution of head nurses emotional intelligence levels (Table $\mathrm{No}=30)$.

\begin{tabular}{lll}
\hline $\begin{array}{l}\text { Level of emotional } \\
\text { intelligence }\end{array}$ & $\mathrm{N}$ & $\%$ \\
\hline Low & 0 & 0 \\
Moderate & 2 & 6.7 \\
High & 28 & 93.3 \\
\hline
\end{tabular}

Table (4): Distribution of staff nurses according to personal characteristics data $(\mathrm{N}=350)$.

\begin{tabular}{lll}
\hline Item & No. & $\%$ \\
\hline Gender: & & \\
Male & 79 & 22.6 \\
Female & 271 & 77.4 \\
Age: & & \\
$20-30$ & 116 & 33.1 \\
$31-40$ & 106 & 30.3 \\
41-50 & 101 & 28.9 \\
51-60 & 27 & 7.7 \\
Educational level: & & \\
Diploma & 196 & 56 \\
Institute & 154 & 44 \\
Years of experience & & \\
as a staff nurse: & & \\
1-10 & 110 & 31.4 \\
11-20 & 100 & 28.6 \\
21-30 & 109 & 31.1 \\
31-40 & 31 & 8.9 \\
\hline
\end{tabular}

Table (5): Mean and standard deviation and mean percent of respondent's perception about emotional intelligence dimension $(\mathrm{N}=30)$.

\begin{tabular}{lccccc}
\hline $\begin{array}{l}\text { Job satisfaction } \\
\text { dimension }\end{array}$ & $\begin{array}{c}\text { Mini- } \\
\text { mum }\end{array}$ & $\begin{array}{c}\text { Maxi- } \\
\text { mum }\end{array}$ & Mean & SD & $\begin{array}{c}\text { Mean } \\
\%\end{array}$ \\
\hline $\begin{array}{l}\text { Supervision } \\
\text { Nature of the work }\end{array}$ & 8 & 40 & 25.6667 & 4.40083 & 64.17 \\
$\begin{array}{l}\text { Communication } \\
\begin{array}{l}\text { Coworker } \\
\text { relationship }\end{array}\end{array}$ & 4 & 20 & 13.2147 & 1.93498 & 66.07 \\
$\begin{array}{l}\text { Promotion } \\
\text { Work pressure }\end{array}$ & 6 & 20 & 13.9525 & 2.71198 & 63.27 \\
\hline
\end{tabular}

Table (6): Frequency distribution of staff nurses job satisfaction levels (Table $\mathrm{No}=350)$.

\begin{tabular}{lll}
\hline $\begin{array}{l}\text { Level of job } \\
\text { satisfaction }\end{array}$ & $\mathrm{N}$ & $\%$ \\
\hline Low & 0 & 0 \\
Moderate & 286 & 80.8 \\
High & 68 & 19.2 \\
\hline
\end{tabular}

Table (7): Correlation between head nurses emotional intelligence and staff nurses job satisfaction.

\begin{tabular}{lcc}
\hline Variables & $r$ & $p$ \\
\hline Emotional intelligence Job satisfaction & 0.359 & $0.052^{*}$ \\
\hline
\end{tabular}

\section{Discussion}

The findings of the current study showed that the majority of them were females. These finding could be due to the dominance of females in the nursing profession and recency of males involvement in nursing. In addition, about half of the sample age ranged between 30 to 40 years old. Further more, the majority of them were married. And more than half of the sample had years of experience as a staff nurse ranged between 10 to 20 years. While the majority of them had experience as ahead nurse ranged between 1 to 10 years, this may be because half of theme's age ranged between 30 to 40 years old and nurses were employed in governmental hospitals after having baccalaureate degree.

There are seven dimensions identified as the components of emotional intelligence: Selfawareness, Emotional self-regulation, Self-motivation, empathy, Stress management, social awareness and self-esteem.

The current study revealed that head nurses had a high level of self awareness. This indicated that they understanding their emotions as they developed an effective self- assessment of feelings and emotions learn from the experience of the past know their strength and weaknesses and they have self confidence.

The previous results was in agreement with a study conducted at King Saud University by [11] who assessed the emotional intelligence and its relation to the stressors of life among nurses the study revealed that participant demonstrated a higher level of self awareness due to they were aware of their feelings and emotions.

Also the results of the study revealed a high level of Emotional self-regulation among the studied head nurses. This may be because they have 
the ability for monitoring, evaluating and modifying emotional reactions in a manner that is socially tolerable and sufficiently flexible.

The results of the current study were matched with a study carried out by [12] that assessed the relationship between emotional intelligence and job satisfaction of physical education teachers. $\mathrm{He}$ found that the participants had high level of emotional self-regulation.

Results revealed that the studied head nurses had a high level of self motivation. This explains the facet that they are able to improve and achieve commitment to their goals and they are initiative. They can complete tasks with energy and high concentration and can apply projects despite some obstacles.

This result is in agreement with the result of the study conducted in Accra by [13] to assess the relationship between emotional intelligence and job satisfaction among nurses he reported that the study participants have a high level of self- motivation.

Furthermore, the results of the current study revealed that there was a good participant responses regarding Empathy dimension. This may be due to the awareness of study participant to their needs and feelings of them selves and others. And part of their course training as a caregiver stress on the importance of being empathizing with patients and they have the ability to consider the differences between people and acting with them according to each situation.

This result was consistent with the results of [14] who conducted a study to assess the influence of emotional intelligence on the quality of care and nurse's work satisfaction. They reported that the study participants had a good level of Empathy, as Empathy is an important multi-dimensional trait of nurses which could be fostered in the early stages of nursing carrier.

A high percentage of the study sample agreed that social awareness was one of the most important dimensions for high emotional intelligence. This may be due to that there was a wide range of relationships among and they have the ability to interact with others feelings and they work on building good relationship with their colleague in the hospital.

These results are in agreement with the results of the study conducted by [15] who reported a high level of attachment among employee in the organ- ization as social awareness is important dimension for emotional intelligence.

Furthermore, the result of the current study revealed that the studied head nurses had a high level of stress management. This was may be due to they have the ability to handle stressful situations, problem solving quietly and had healthy coping strategies and psychological stability.

On the same line [13] who studied the relationship between emotional intelligence, job satisfaction and organizational commitment. He reported that the participant demonstrated a higher level of stress management due to their experience and effective time management.

The study participants showed a high level of self-esteem. These are due to self confidence, their ability for making self-evaluation, determine their goals and updating.

This finding matched with the findings of the study about the relationship between emotional intelligent and academic achievement that conducted by [9] who reported that the student had high self-esteem.

In addition, regarding to levels of emotional intelligence of study participants, results of the current study revealed that the majority of them had a high level of emotional intelligence. These might be due to many factors at the beginning cultural, environmental and social support factors which help them to be aware of their emotions also aware by needs and feelings of others and might be due to knowledge and skills which acquired from practical and theoretical nursing courses, exposure to emergency and critical situations.

The previous results was in agreement with the study that conducted by [16] these results indicated that employees had a higher level of emotional intelligence this enables employees to be able to take action and more aware of the factors that contribute to their experience of positive and negative emotions about their jobs.

Regarding to the socio-demographic data of the staff nurses, the results of the current study revealed that the majority of the study sample was females this may be due to recency of males involvement in nursing. Also more than half of them were diploma nurses that are because their numbers are much than baccalaureate nurses. About one third of the study sample had experience ranged from 1 to 10 years. And one third of the sample ages ranged between 20 to 30 years old and they 
had the chance to employ in governmental hospitals after having diploma degree. Most of them worked in the medical department which was a department for critically ill patients who need more nursing care hours.

Job satisfaction was classified into six dimensions as follow: Supervision, nature of the work, communication, co-workers relationship, promotion and work pressure.

Regarding to supervision dimension the current study revealed that about more than half of the study sample was moderately satisfied with supervision at their working place this may be because they have the chance to be responsible for planning their work and supervision gives the staff the mean to develop professional skills, judgment to achieving growth in order to improve the standers of service.

This result opposes other study, who reported that the majority of the staff nurses in Philadelphia department of behavioral health and mental retardation services were highly satisfied with supervision [17]

The current study revealed that more than half of the staff nurses were moderately satisfied with the nature of the work. This may be due to the staff nurses like their job and the task is fulfilling and they are pride in doing their job. This results was in contradiction with [18], who reported that half of the professional nurses in Thailand were highly satisfied with the work it self.

Communication is an important dimension of job satisfaction the current study revealed that there was a moderate level of communication this may be due to the goal of the organization clear to the staff nurses and their orientation to what is going on the organization and they establish empathetic relationship and effective communication with others and create work groups in order to perform their duties.

The result of the study were matched with [19] who reported that the majority of nurses experiencing positive relationship with supervisors.

The current study stated that the majority of the staff nurses were highly satisfied with coworkers relationships. This may be due to the employees have good relationships with their coworkers and the importance of team work and team spirit in nursing job.

This results in the same line with the study conducted by [20] who stated that nurses works for long hours every day and have the same goal which make them all together grouped to maintain patient's life, recover from illness providing care and discharging healthier individual.

The current study revealed moderate level of satisfaction about promotion dimension it my be due to decreased career advancement opportunities and diploma nurses and associate degree nurses remain as staff nurses as long as they work.

These results on the same line with [10] who revealed that staff nurses are not satisfied with promotions as promotion are limited to bachelor nurses only.

Work pressure is an important factor of job satisfaction as the majority of the study agreed that they are suffering from work pressure. This may be due to shortage of the staff nurses and insufficient nurse patient ratio also too much paper work or documentation of none nursing and secretary papers added to the patient care activities make the staff nurse in severe pressure as they need to provide both care and documentation for each individual patient.

These results are consistent with [21] who revealed that high work loads and shortage of nurses were major factors that caused job dissatisfaction among nurses. Also [22] who reported that when bed side nurse experience overload and become dissatisfied they decide to leave employment in hospitals.

In addition, regarding to levels of job satisfaction of study participants, results of the current study revealed that the majority of them had a moderate level of job satisfaction.

The result of [23] supported me which stated that level of job satisfaction among employees of Egyptian private universities were at moderately level. Also [24] stated that there was a higher level of job satisfaction associated with greater ranked efficiency, effectiveness, productivity and profitability increases in job satisfaction have been linked to more positive work environment improved culture, higher rate of worker retention and finally with institutions.

The result of the current study revealed that there is positive relationship between emotional intelligence and job satisfaction. This is in the same line with the study conducted by [25] that revealed there was a positive relationship between emotional intelligence and job satisfaction also the result of [26] showed direct correlation between 
emotional intelligence and job satisfaction of Primary health care providers (behvarz) in sisten region in Iran.

\section{Conclusion:}

The present study concluded that there was a relationship between head nurses' emotional intelligence and staff nurses' job satisfaction.

Regarding to emotional intelligence the study sample has high level with the mean percent $84.5 \%$. This may be due to have the ability to perceive him and others emotion and they have the ability to use memory, knowledge, experience, understanding, reasoning, imagination and judgment in order to solve problems and adapt to new situations. About $66.7 \%$ of head nurses are females and the most of them ranged between 30 to less than 40 years old and the majority have years of experience as a head nurse ranged between 1 to less than 10 years. Regarding to job satisfaction the study sample has moderate job satisfaction with the mean percent $65.7 \%$. This may be due to this may be due to good relationship with their colleague and their supervisor in the hospital. About $77.4 \%$ of staff nurses are female and about $56 \%$ of them are diploma nurses.

\section{Recommendations:}

In the light of the findings of the present study, the following are recommended:

- Health care organization should implement programs on emotional intelligence for head nurses and other staff nurses.

- Job satisfaction of the nurses at any health care organization should be periodically measured and analyzed then area of dissatisfaction should be handled by the managers whenever possible. That is in order to assure employees commitment, productivity and to lower absenteeism rates.

- Hospitals should put a criteria for selection nurse manager who have the experience and the ability to handle all levels of emotional intelligence for nurses which will improve levels of job satisfaction and quality of care and hospital reputation.

- Opportunities for further research should be made to investigate factors that affect emotional intelligence and job satisfaction.

- Manager should build and maintain a team work spirit as well as keeping a positive work climate.

- Manager should adopt a system of promotion and rewarding to recognize and appraise distinguished staff.
- A longitudinal study should be performed to examine changes in emotional intelligence of head nurses to determine if EI increases based on their experience with their peers and hospital members

\section{References}

1- COETZEE M. and SCHREUDER A.M.G.: The relation between career anchors, emotional intelligence and employability satisfaction among workers in service industry. Southern African Business Review, 15 (3): 76-97, 2011.

2- SHARMA T. and SEHRAWAT A.: Emotional Intelligence, Leadership and Conflict Management: LAP LAMBERT Academic Publishing, 2014.

3- La GRANDEUR K.: Emotion, Artificial Intelligence and Ethics. Beyond Artificial intelligence, Springer, 97-109, 2015.

4- ATTABI Y. and DUMOUCHEL P.: Anchor models for emotion recognition from speech. Affective Computing, IEEE Transactions On, 4 (3): 280-290, 2013.

5- LORBER M. and SKELA SAVIC B.: Job Satisfaction of nurses in Solvenian hospitals, Creation medical Journal, 53 (3): 263-270, doi: 10, 3325/cmj. 2012.53.263 PMID: 22661140, 2012.

6- GHOREISHI F., ZAHIRRODINE A., MOOSAVI S. and MEHRIZI M.: Evaluation of Emotional Intelligence and Job satisfaction in Employees of Kashan Hospital.

7- HABIBI M., FESHARAKI M.G., JAMALI M.J. and MOHAMADIAN M.: Factors Affecting on Military Medical Job Satisfaction Staff. Scimetr, 3 (2), 2015.

8- GRORGE J.M. and EALIAS A.: "Emotional and Leadership: The role of emotional intelligence", Vol. 01, pp 1027-1055, 2012

9- NASR T. and ABD-ELHAMIED M.: Relationship between emotional intelligence and academic achievement among undergraduate nursing students, p (52-53), 2015.

10- AMR S. and FEKRY N.: Relationship between job satisfaction and organizational commitment, 2011.

11-AL-ZAHRANI A.A.: Emotional intelligence and its relation to the stressors of life. Dirasat:Human and Social Sciences, 41 (3), 2014.

12- MOUSAVI S.H., YARMOHAMMADI S., NOSRAT A.B. and TARASI Z.: The relationship between emotional intelligence and job satisfaction of physical education teachers. Annals of Biological Research, 3 (2): 780-788, 2012.

13- ANARI N.N.: Teachers: Emotional intelligence, Job satisfaction and organizational commitment. Journal of work place learning, 24 (4): 256-269. doi: 10.1108/1366 9621211223379,2012

14- BUTKIEWICK A. and KASZKOWIAK K.: The influence of emotional intelligence on the quality of care and nurses work satisfaction." Pieleg Pol., (2): 81-5, 2010.

15- EMDADY M. and BAGHERI N.: The relation between emotional intelligence and job satisfaction. European Journal of Experimental Biology, 3 (1): 554-558, 2013.

16- CERIT E. and BESER N.G.: Levels of Emotional Intelligence of nurses. International Journal, 7 (3): 936, 2014. 
17- PILLAY R.: Work satisfaction of professional nurses in south Africa: Acomparative analysis of the public and private sectors. Human resources for health, 7,15. doi: 10.1186/1478-4491-7-15, 2009.

18- RAVARI A.L.I., BAZARGAN M.,VANAKI Z. and MIRZAEI T.: Job satisfaction among Iranian hospital-based practicing nurses: Examining the influence of selfexpectation, social interaction and organizational situations. Journal of nursing Management, 20 (4): 522-533, Rickard, 2012.

19- TOURANGEAU A., PATTERSON E., ROWE A., SAARI M., THOMSON H., MACDONALD G. and SQUIRES, M.: Factors influencing home care nurse intention to remain employed. Journal of Nursing Management, 22 (8): 1015-1026, 2014.

20- SALAH H.: Relationship between Job satisfaction, professional image and nurses marketing of the nursing profession, p (66-70), 2017.

21- ATEFI N., ABDULLAH K.L., WONG L.P. and MAZLOM R.: Factors influencing registered nurses perception of their overall job satisfaction: A qualitative study. International nursing review, 61 (3): 352-360 2014.
22- ROUNTREE B.H. and PORTER R.: The experience of work in hospital settings and nurse's perceived need or desire to look for a less stressful, more satisfying job, international journal of organization theory and behavior, 12 (1): 1, 2009.

23- MOHAMED S. and EZZ-ELDEEN N.: Relationship between staff nurses job satisfaction and organizational commitment at new El Kasar El Ani Teatching Hospital, p (41-43), 2011.

24- AQIL M., MUNIR S.S., AHMED R.R. and QADEER S.: Factors influencing insurance agents' intention to leave: Finding from life insurance sector in Pakistan. International Journal of marketing and technology, 4: 204-212, 2014.

25- BOAFO I.M., HANCOCK P. and GRINGART E.: Nursing open journal 2017 April 4 (2): 84-89, Puplished 2016 Nov. 6, Doi:10.1002/nap2.70, 2014.

26- RAHMATI A.: Relationship between emotional intelligence and job satisfaction of primary health care providers (behavars), 2016.

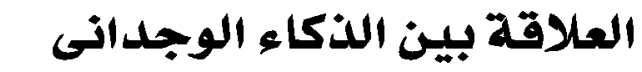 لرئيسات التمريض والرضن الركاء الوجلوظيفى الوظى}

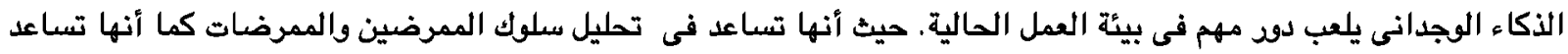

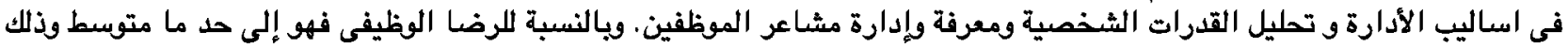

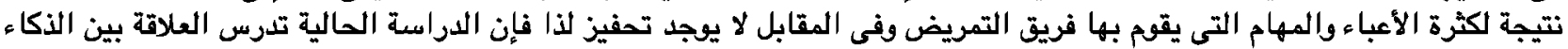

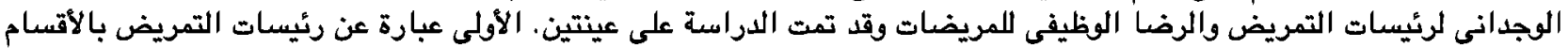

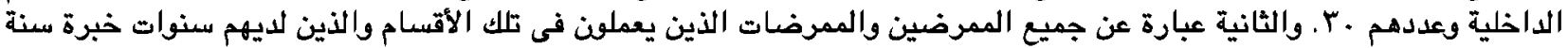

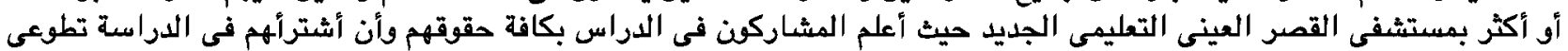

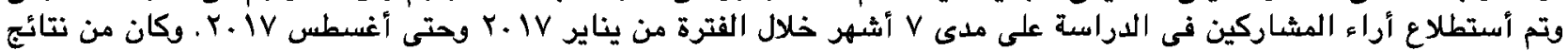

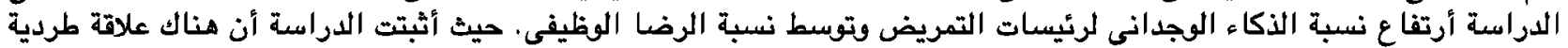

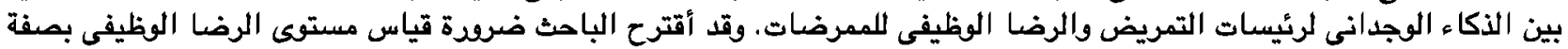

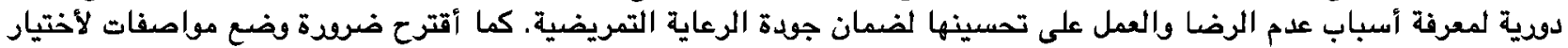

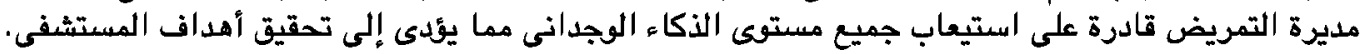

